\title{
Sifat Fisis dan Mekanis Oriented Strand Board Hibrida Bambu Pada Berbagai Shelling Ratio \\ (Physical and Mechanical Properties of Hybrid Bamboo Oriented Strand Board at Various Shelling Ratios)
}

\author{
Rynaldo Davinsy ${ }^{1}$, Elvara D Satria ${ }^{1}$, Muhammad I Maulana ${ }^{1}$, Deded S Nawawi ${ }^{1}$, Rita K \\ Sari $^{1}$, Sena Maulana ${ }^{2}$, Wahyu Hidayat ${ }^{3}$, Fauzi Febrianto ${ }^{1 *}$ \\ ${ }^{1}$ Departemen Hasil Hutan, Fakultas Kehutanan, Institut Pertanian Bogor \\ ${ }^{2}$ Program Studi Rekayasa Kehutanan, Institut Teknologi Sumatera \\ ${ }^{3}$ Jurusan Kehutanan, Fakultas Pertanian, Universitas Lampung \\ *Penulis korespondensi: febrianto76@yahoo.com
}

\begin{abstract}
Hybrid Bamboo Oriented Strand Boards (OSB) were produced to improve bamboo OSB's physical and mechanical properties. Shelling ratio adjustment of the strand type combination could determine the optimal physical and mechanical properties of hybrid bamboo oriented strand boards (OSB). The purpose of this study was to evaluate the physical and mechanical properties of hybrid betung and andong bamboos OSB at various shelling ratios. Steam modified strands of betung and andong bamboo were used as an outer layer and core layer, respectively. Hybrid bamboo OSBs were prepared with $0.7 \mathrm{~g} \mathrm{~cm}^{-3}$ target density and $8 \%$ phenolformaldehyde resin content. Three layers of OSB were made with outer: core shelling ratios of 30:70, 40:60, 50:50, and 60:40. The physical and mechanical properties of the OSB were tested referring to the JIS A 5908-2003 standard. The targeted board density was achieved and the physical properties of all hybrid bamboo OSB have met the requirement of CSA O437.0 (Grade O-1) standard criteria. The parallel modulus of elasticity (MOE) and modulus of rupture (MOR) increased with increasing outer layer ratio. However, the perpendicular MOE and MOR decreased with increasing outer layer ratio. The internal bonding (IB) of the OSB with a shelling ratio of 30:70 and 40:60 met with the requirement of the CSA O437.0 (Grade O-1) standard.
\end{abstract}

Keywords: andong, bamboo, betung, hybrid, oriented strand board

\begin{abstract}
Abstrak
Oriented Strand Board (OSB) hibrida bambu diproduksi untuk meningkatkan sifat fisis dan mekanis OSB bambu. Kombinasi jenis untai yang menghasilkan sifat fisis dan mekanis OSB hibrida optimal dapat diketahui dengan pengaturan shelling ratio. Tujuan dari penelitian ini adalah untuk mengevaluasi sifat fisis dan mekanis OSB hibrida dari bambu Betung dan Andong pada berbagai shelling ratio. Untai bambu Betung dan Andong dengan modifikasi steam masing-masing digunakan sebagai lapisan luar dan lapisan inti. OSB hibrida bambu dibuat dengan kerapatan target $0,7 \mathrm{~g} \mathrm{~cm}^{-3}$ dan kadar perekat phenol formaldehida $8 \%$. Tiga lapis OSB dibuat dengan shelling ratio luar:inti yaitu 30:70, 40:60, 50:50, dan 60:40. Pengujian sifat fisis dan mekanis mengacu pada standar JIS A 5908-2003. Kerapatan papan telah mencapai kerapatan target. Sifat fisis seluruh OSB hibrida bambu ini telah memenuhi kriteria standar CSA O437.0 (Grade O-1). Nilai modulus elastisitas (MOE) dan modulus patah (MOR) sejajar meningkat dengan bertambahnya nisbah lapisan luar. Sebaliknya, nilai MOE dan MOR tegak lurus turun ketika nisbah lapisan luar meningkat. Keteguhan rekat internal (IB) yang memenuhi standar CSA O437.0 (Grade O-1) terdapat pada OSB dengan shelling ratio 30:70 dan 40:60.
\end{abstract}

Kata kunci: Andong, bambu, Betung, hibrida, oriented strand board 


\section{Pendahuluan}

Bambu merupakan bahan berlignoselulosa yang telah banyak diketahui sebagai substitusi kayu. Ketersediaan bambu yang melimpah membuat bambu memiliki prospek yang baik untuk dikembangkan (Maulana 2019a). Menurut Badan Pusat Statistik (2019), bambu tersebar di seluruh pulau yang ada di Indonesia terutama di Pulau Jawa, Bali, Nusa Tenggara, Sumatera, dan Sulawesi dengan produksi mencapai \pm 20 juta batang pada tahun 2018. Jenis bambu yang telah ditemukan di Indonesia saat ini sekitar 161 jenis dan berpeluang menjadi lebih banyak apabila diidentifikasi dengan baik (Widjaja et al. 2014). Selain ketersediaan yang melimpah, keunggulan bambu lainnya yaitu laju pertumbuhan yang cepat, daur yang pendek, keteguhan tarik yang tinggi, dan dapat ditanam di hampir seluruh jenis tanah kecuali daerah berpasir seperti pantai (Febrianto et al. 2017). Dibalik keunggulannya, bambu memiliki kelemahan yaitu diameter yang kecil sehingga pemanfaatan dalam hal konstruksi sangat terbatas, keteguhan belah yang rendah, variabilitas sifat fisis yang tinggi antar bagian pangkal, tengah, dan ujung sehingga sulit digunakan sebagai bambu solid. Oleh karena itu, alternatif pemanfaatan bambu yang tepat adalah dengan mengkonversi bambu menjadi produk komposit.

Produk komposit meningkatkan pemanfaatan bambu untuk bahan bangunan struktural maupun non struktural. Salah satu produk komposit yang saat ini sedang berkembang adalah Oriented Strand Board (OSB). OSB adalah panel komposit yang terbuat dari bahan untai yang memanjang, tipis, dan tidak lebar yang disusun saling tegak lurus dan direkat dengan perekat eksterior kemudian dikempa panas dengan suhu tertentu (Maulana 2018, SBA 2005). Penelitian OSB bambu telah banyak dilakukan dan menghasilkan OSB bambu dengan sifat fisis jauh lebih baik dari OSB kayu dan memenuhi kriteria OSB komersial (Febrianto et al. 2012, 2013, Adrin et al. 2013, Maulana et al. 2019). Selain itu, OSB bambu juga memiliki sifat mekanis yang unggul. Sifat fisis dan mekanis OSB bambu yang unggul salah satunya disebabkan oleh perlakuan awal yang diterapkan pada untai. Perlakuan awal steam dan pembilasan $\mathrm{NaOH} \quad 1 \%$ dapat meningkatkan sifat fisis dan mekanis juga keawetan dari OSB (Adrin et al. 2013, Maulana et al. 2016, Maulana et al. 2018, Fatrawana et al. 2019). Beberapa penelitian mengenai OSB bambu tersebut menunjukkan OSB yang dibuat dari bambu Betung dan Andong secara tunggal telah memenuhi kriteria standar CSA O437.0. Namun, penelitian OSB bambu yang dibuat dari kombinasi dua jenis bambu tersebut belum pernah dilaporkan.

OSB hibrida bambu yang dibuat dari dua jenis bambu diharapkan dapat memiliki sifat-sifat yang lebih baik dari pada OSB bambu tunggal. Selain itu, penggunaan lebih dari satu jenis bambu sebagai bahan baku OSB dapat mengurangi ketergantungan pemanfaatan pada satu jenis bambu tertentu. Akan tetapi, kombinasi dua jenis bambu perlu ditentukan untuk menghasilkan kualitas OSB hibrida bambu yang unggul dan memenuhi standar. Penentuan kombinasi jenis bambu dapat dilakukan dengan mengatur shelling ratio OSB. Shelling ratio merupakan nisbah lapisan luar dan dalam pada OSB. Menurut Maloney (1993) struktur lapisan merupakan salah satu faktor yang mempengaruhi sifatsifat papan partikel. 
Penelitian pada OSB bambu tunggal dengan shelling ratio $67: 33$ atau perbandingan face:core:back 1:1:1 memiliki perbedaan nilai kekuatan sejajar dan tegak lurus serat yang berbeda sangat jauh (Maulana et al. 2017). Penelitian selanjutnya pada OSB tunggal bambu Betung dan Andong menunjukkan bahwa peningkatan shelling ratio dapat meningkatkan kekuatan lentur pada arah sejajar dan sebaliknya menurunkan kekuatan lentur pada arah tegak lurus (Maulana et al. 2019). Oleh karena itu, kajian mengenai shelling ratio pada OSB hibrida bambu menarik untuk dilakukan. Pada penelitian ini, sifat fisis dan mekanis OSB hibrida bambu dari untai bambu Betung dan Andong dievaluasi pada empat pengaturan shelling ratio.

\section{Bahan dan Metode}

Persiapan bahan baku dan pembuatan OSB hibrida bambu Betung (Dendrocalamus asper) dan Andong (Gigantochloa psedoarundinacea) mengacu berdasarkan Maulana et al. (2017). Bambu dikonversi menjadi untai yang memiliki kerapatan berturut-turut yaitu $0,52 \mathrm{~g} \mathrm{~cm}^{-3}$ dan $0,60 \mathrm{~g} \mathrm{~cm}^{-3}$ untuk bambu Betung dan Andong, dengan target dimensi untai yaitu $(70 \times 25 \times 0,5)$ $\mathrm{mm}^{3}$ (panjang $\mathrm{x}$ lebar $\mathrm{x}$ tebal). Untai diberi perlakuan steam pada suhu $126{ }^{\circ} \mathrm{C}$ dan tekanan 0,14 MPa selama 1 jam. Untai yang telah disteam kemudian dibilas dengan larutan $\mathrm{NaOH} 1 \%$. Kemudian untai dikeringudarakan selama tujuh hari dan dioven pada suhu $60{ }^{\circ} \mathrm{C}$ selama 3 hari untuk mencapai kadar air (KA) di bawah 5\%.

OSB hibrida bambu dibuat dengan kerapatan target $0,7 \mathrm{~g} \mathrm{~cm}^{-3}$ dan kadar perekat fenol formaldehida $8 \%$. OSB hibrida bambu dibagi menjadi 3 lapisan (face: core: back) (Betung: Andong:
Betung). Untai bambu dicampurkan dengan perekat menggunakan sprayer gun. Untai yang telah diberikan perekat kemudian ditambahkan paraffin sebanyak $1 \%$ dari berat bahan baku. Untai disusun saling tegak lurus satu dengan yang lainnya, dengan volume target berukuran $(30 \times 30 \times 0,9) \mathrm{cm}^{3}$ (panjang $\mathrm{x}$ lebar $\mathrm{x}$ tebal). Shelling ratio (luar:inti) yang digunakan dalam pembuatan OSB adalah 30:70, 40:60, 50:50, dan 60:40. Lapisan untai yang telah disusun kemudian ditekan menggunakan kempa panas pada suhu $135{ }^{\circ} \mathrm{C}$ dengan tekanan spesifik 2,45 $\mathrm{MPa}$. OSB hibrida bambu kemudian dikondisikan selama \pm 14 hari.

Prosedur dan perhitungan parameter pengujian sifat fisis dan mekanis OSB mengacu pada Febrianto et al. (2015). Pengujian sifat fisis dan mekanis OSB mengunakan standar JIS A 5908:2003 (JSA 2003). Parameter sifat fisis yang di uji meliputi kerapatan, kadar air (KA), daya serap air (DSA), dan pengembangan tebal (PT). Sementara itu, sifat mekanis yang dievaluasi adalah modulus elastisitas (MOE) sejajar dan tegak lurus serat, modulus patah (MOR) sejajar dan tegak lurus serat, serta keteguhan rekat internal (IB). Sifat fisis dan mekanis OSB hibrida bambu kemudian dibandingkan dengan standar komersial OSB CSA O437.0 (Grade O1) (SBA 2005).

Data dianalisis dengan Rancangan Acak Lengkap (RAL) sederhana faktor tunggal, yaitu shelling ratio dengan empat taraf (30:70, 40:60, 50:50, dan 60:40). Pengaruh perlakuan dianalisis pada taraf nyata $5 \%$. Jika hasil analisis tersebut menunjukan pengaruh yang nyata, uji lanjut Duncan digunakan untuk melihat pengaruh perlakuan yang berbeda nyata. 


\section{Hasil dan Pembahasan}

\section{Sifat fisis OSB hibrida bambu}

\section{Kerapatan dan kadar air}

Kerapatan merupakan nisbah antara volume dengan berat kering udara papan (Adrin et al. 2013). Kerapatan sangat berpengaruh terhadap sifat fisis dan mekanis papan (Maloney 1993). Nilai kerapatan OSB hibrida bambu ini berkisar diantara 0,70 hingga $0,71 \mathrm{~g} \mathrm{~cm}^{-3}$ (Tabel 1). Secara umum kerapatan OSB hibrida bambu ini telah memenuhi kriteria kerapatan target yaitu sebesar 0,7 $\mathrm{g} \mathrm{cm}^{-3}$. Dengan demikian papan yang dihasilkan memiliki kerapatan yang homogen.

Kadar air merupakan kandungan air papan pada kondisi kesetimbangan dengan lingkungannya. Bowyer et al. 2003 mendefinisikannya sebagai berat air terhadap berat kayu bebas air atau kering tanur yang dinyatakan sebagai persen. Nilai KA OSB hibrida bambu pada penelitian ini adalah 10,12-11,36\% (Tabel 1). KA ini sedikit lebih tinggi dibandingkan dengan KA OSB bambu Andong dan Betung yaitu sebesar 8,9910,33\% (Maulana 2019). Namun, nilai KA ini telah memenuhi syarat JIS A 5908:2003 yang mensyaratkan bahwa nilai KA papan 5-13\%. Perbedaan kadar air ini dipengaruhi respon masingmasing OSB dalam menyerap air sesuai dengan lingkungannya (Febrianto et al. 2017).

Tabel 1 Kerapatan dan kadar air OSB hibrida bambu Betung dan Andong pada berbagai shelling ratio

\begin{tabular}{cccc}
\hline No & $\begin{array}{c}\text { Shelling } \\
\text { ratio }\end{array}$ & $\begin{array}{c}\text { Kerapatan, } \\
\mathrm{g} \mathrm{cm}^{3}\end{array}$ & $\begin{array}{c}\text { Kadar Air, } \\
\%\end{array}$ \\
\hline 1. & $30: 70$ & $0,70 \pm 0,03$ & $11,36 \pm 0,29$ \\
2. & $40: 60$ & $0,72 \pm 0,01$ & $10,12 \pm 0,44$ \\
3. & $50: 50$ & $0,71 \pm 0,04$ & $10,74 \pm 0,77$ \\
4. & $60: 40$ & $0,71 \pm 0,03$ & $11,30 \pm 0,43$ \\
\hline
\end{tabular}

\section{Pengembangan tebal dan daya serap air}

Pengembangan tebal merupakan penambahan dimensi tebal papan setelah perendaman. Salah satu hal yang mempengaruhi PT adalah DSA. Daya serap air merupakan kemampuan OSB untuk menyerap air setelah dilakukan perendaman. Gambar 1 Menampilkan nilai PT dan DSA setelah direndam dalam air selama 24 jam. Nilai PT OSB hibrida bambu yaitu 10,74-13,97\% . Sedangkan DSA menunjukan nilai sebesar 29,52-31,45\%. Persentase PT dan DSA terendah terdapat pada shelling ratio 60:40 dan tertinggi 30:70 dimana ditengahnya adalah bambu Andong (Gambar 1).

Gambar 1 menunjukan bahwa semakin besar bagian inti OSB maka semakin besar juga PT dan DSA, karena pada shelling ratio 60:40 bagian luar seimbang dan lebih banyak dibandingkan dengan 30:70. Nilai DSA dan PT papan akan meningkat seiring dengan rendahnya lapisan muka (Cheng et al. 2012). Hal tersebut dikarenakan bagian permukaan bambu Betung memiliki dua bagian fiber bundle dibandingkan bambu Andong yang hanya memiliki satu bagian (Febrianto et al. 2017). Bambu Betung memiliki stabilitas dimensi yang baik dibandingkan dengan bambu Andong. Oleh karena itu penyerapan air pada bambu Betung akan lebih sulit dari bambu Andong. Penjelasan tersebut memperjelas bahwa semakin meningkatnya lapisan permukaan OSB hibrida bambu Betung dan Andong akan meningkatkan stabilitas dimensinya. Dengan kata lain, menurunnya nilai PT dan DSA (Febrianto et al. 2015, Maulana 2019b). Meskipun demikian, seluruh OSB hibrida bambu pada penelitian ini telah memenuhi standar CSA 0437.0 (Grade O-1) yang mensyaratkan nilai pengembangan tebal OSB $\leq 15 \%$. 


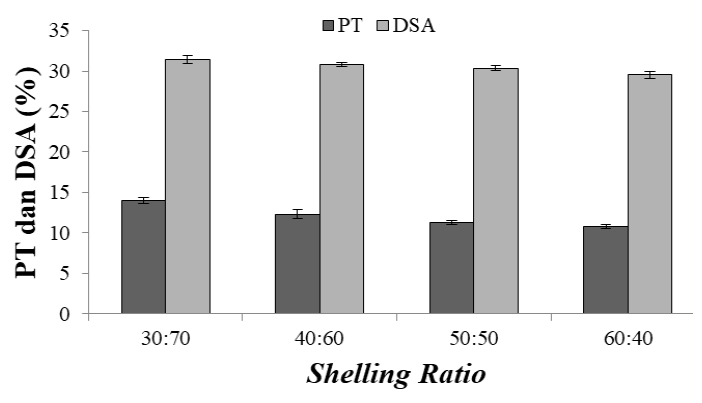

Gambar 1 Daya serap air dan pengembangan tebal OSB hibrida bambu pada berbagai shelling ratio.

\section{Sifat mekanis OSB hibrida bambu}

\section{Modulus elastisitas}

Nilai MOE sejajar serat dan tegak lurus pada OSB hibrida bambu berturut-turut adalah 2239-6527 MPa dan 1194-3529 MPa (Gambar 2). Nilai MOE sejajar serat tertinggi diperoleh pada OSB dengan shelling ratio 60:40. Semakin kecil nilai MOE sejajar serat yang terjadi disebabkan oleh menebalnya lapisan inti OSB (Avramidis dan Smith 1989, Saad dan Hilal 2012). Maulana et al. (2016) melaporkan bahwa semakin tinggi shelling ratio OSB maka MOE sejajar serat akan semakin tinggi dan MOE tegak lurus serat menurun. Nilai MOE sejajar serat telah memenuhi kriteria OSB komersial CSA 0437.0 (Grade O-1) yaitu pada shelling ratio 50:50 dan 60:40. Hal sebaliknya terjadi pada MOE tegak lurus serat, nilai tertinggi diperoleh pada OSB dengan shelling ratio 30:70. Sedangkan pada MOE tegak lurus hanya shelling ratio 60:40 yang tidak memenuhi kriteria OSB komersial. Febrianto et al. (2017) melaporkan bahwa OSB memiliki nilai kekuatan lentur yang tinggi dikarenakan bagian permukaan OSB yang dijadikan contoh uji MOE sejajar serat memiliki untai yang sejajar. Hal yang sama terjadi pada MOE tegak lurus, bahwa semakin tebal

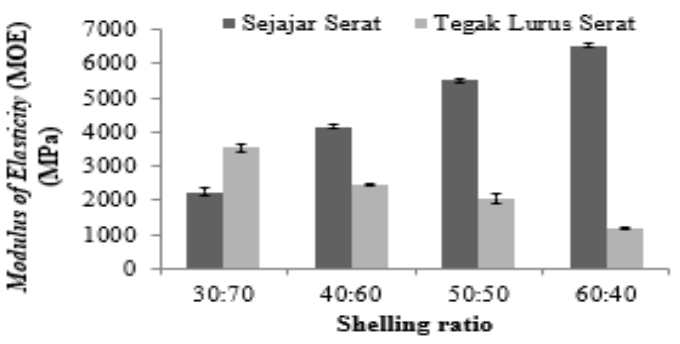

Gambar 2 Nilai MOE sejajar dan tegak lurus serat dari OSB hibrida bambu pada berbagai shelling ratio.

lapisan inti maka akan semakin kuat (Febrianto et al. 2017).

\section{Modulus patah}

Nilai MOR sejajar dan tegak lurus OSB hibrida bambu berturut-turut adalah 10,61-27,71 MPa dan 15,22-23,81 MPa (Gambar 3). Nilai MOR sejajar serat pada OSB hibrida bambu dengan shelling ratio 40:60, 50:50, dan 60:40 telah memenuhi syarat CSA 0437.0 (Grade O-1). Sementara itu, seluruh MOR tegak lurus telah memenuhi syarat kriteria CSA 0437.0 (Grade O-1).

Hasil analisis keragaman menunjukkan adanya pengaruh nyata shelling ratio terhadap MOR. Hasil pengujian MOR sejajar serat menunjukkan semakin tinggi rasio lapisan permukaan dibandingkan inti, akan meningkatkan MOR sejajar serat. Namun, hal sebaliknya terjadi pada pengujian MOR tegak lurus. Pengujian MOR tegak lurus menunjukkan semakin tinggi rasio lapisan permukaan akan menurunkan nilai MOR tegak lurus serat. Febrianto et al. (2017) menegaskan pernyataan tersebut dengan semakin tebal lapisan permukaan maka semakin tinggi nilai MOR sejajar serat. Akan tetapi, nilai MOR tegak lurus akan menurun apabila bagian permukaan OSB semakin tebal. 


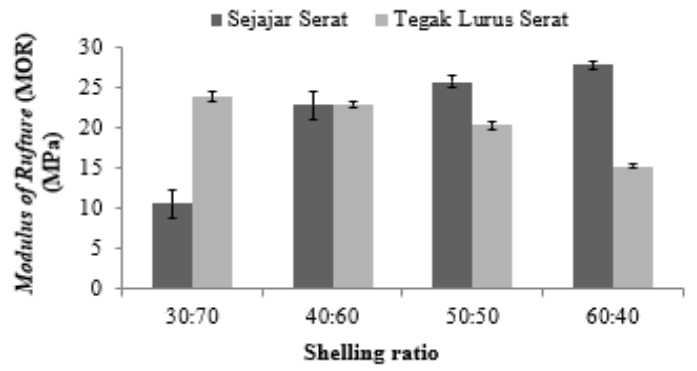

Gambar 3 Nilai MOR sejajar serat dan tegak lurus serat dari OSB hibrida bambu sejajar serat pada berbagai shelling ratio.

\section{Keteguhan rekat internal}

Keteguhan rekat internal merupakan kekuatan tarik tegak lurus permukaan panel serta ukuran tunggal terbaik kualitas panel karena mengindikasikan kekuatan ikatan antar untai. Nilai IB ratarata berkisar antara 0,29-0,36 $\mathrm{MPa}$ (Gambar 4). Nilai IB tertinggi dan terendah berturut-turut pada shelling ratio 30:70 dan 60:40. Nilai IB menurun seiring dengan meningkatnya rasio lapisan permukaan. Dengan kata lain bertambahnya komposisi untai Andong pada bagian inti berdampak kepada peningkatan nilai IB. Hasil uji statistik menunjukkan adanya pengaruh nyata shelling ratio terhadap IB papan yang dihasilkan. Hal ini diduga disebabkan oleh gradien kerapatan vertikal yang tinggi (Kawai et al. 1985). Sehingga akan menimbulkan kepadatan yang tinggi. Kerapatan berpengaruh terhadap keteguhan rekat internal, dimana proses pengempaan yang cepat membuat bagian permukaan akan memiliki kerapatan yang tinggi dibandingkan dengan bagian inti. Namun, daya rekat internal tidak dipengaruhi struktur lapisan (Sumardi et al. 2007). Sebagaimana kerapatan yang tinggi bagian permukaan akan menghasilkan kekuatan MOE dan MOR terutama sejajar serat tinggi, namun memiliki nilai IB yang rendah (Maulana 2019a).

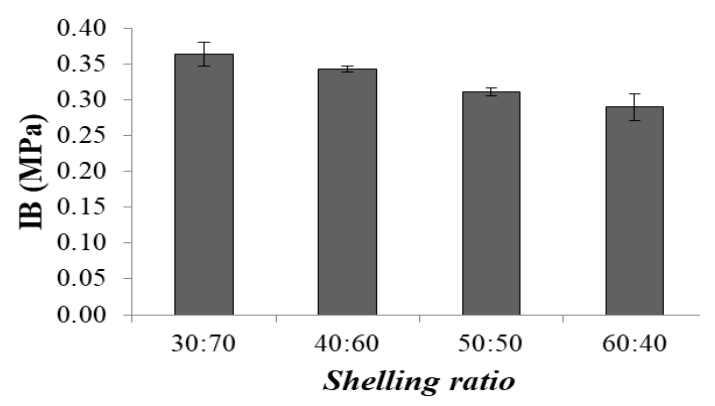

Gambar 4 Nilai Internal Bonding OSB hibrida bambu pada berbagai shelling ratio.

\section{Kesimpulan}

Perbedaan shelling ratio mempengaruhi sifat fisis dan mekanis dari OSB hibrida bambu yang dihasilkan. Sifat fisis pada hibrida ini telah memenuhi kriteria. Nilai MOE dan MOR sejajar serat akan meningkat nilainya seiring dengan bertambah tebal lapisan luar. Sebaliknya MOE dan MOR tegak lurus akan menurun nilainya apabila lapisan luar bertambah tebal. Keteguhan rekat internal (IB) yang dihasilkan yang memenuhi kriteria yaitu pada shelling ratio 30:70 dan 40:60. OSB hibrida bambu dengan shelling ratio 50:50 memiliki sifat fisis dan mekanis yang telah memenuhi kriteria standar CSA 0437.0 (Grade O-1).

\section{Ucapan Terima Kasih}

Terima kasih kepada Direktorat Pendidikan Tinggi, Kementrian Riset, Teknologi, dan Pendidikan Tinggi Republik Indonesia yang telah mendanai penelitian ini melalui skema Penelitian Terapan

(Nomor: 3/E1/KP.PTNBH/2019).

\section{Daftar Pustaka}

Adrin, Febrianto F, Sadiyo S. 2013. Properties of oriented strand board prepared from steam treated bamboo 
strands under various adhesive combinations. JITKT. 11(2):109-119.

Avramidis S, Smith LA. 1989. The effect of resin content and face to core ratio on some properties of oriented strand board. Holz. 43(2):131-133.

[BPS] Badan Pusat Statistik. 2019. Statistik Produksi Kehutanan. Jakarta: Badan Pusat Statistik.

Chen S, Fang L, Liu X, Wellwood R. 2008. Effect of mat structure on modulus of elasticity of oriented strandboard. Wood Sci. Technol. 42(3):197-210.

Cheng Y, Guan M, Zhang Q. 2012. Selected physical and mechanical properties of bamboo and poplar composite OSB with different hybrid ratios. Key Engineering Material. 517: 87-95.

Fatrawana A, Maulana S, Nawawi DS, Sari RK, Hidayat W, Park SH, Febrianto F, Lee SH, Kim, N. H. 2019. Changes in chemical components of steam-treated Betung bamboo strands and their effects on the physical and mechanical properties of bamboo-oriented strand boards. Eur. J. Wood Wood Prod. 77(5):731-739.

Febrianto F, Jang JH, Lee SH, Santosa IA, Hidayat W, Kwon JH, Kim NH. 2015. Effect of bamboo species and resin content on properties of oriented strand board prepared from steam treated bamboo strands. Bio Resources. 10(2):2642-2655.

Febrianto F, Purnamasari I, Arinana, Gumilang A, Kim NH, 2013. Steaming effect on natural durability of bamboo-oriented strand board against termites and power post beetle. JITKT. 11(2):161-169.
Febrianto F, Sahroni, Hidayat W, Bakar ES, Kwon GJ, Kwon JH, Kim NH. 2012. Properties of oriented strand board made from Betung bamboo (Dendrocalamus asper (Schultes.f) Backer ex Heyne). Wood Sci Technol 46:53-62.

Febrianto F, Sumardi I, Hidayat W, Maulana S. 2017. Papan Untai Bambu Berarah Material Unggul Untuk Komponen Bangunan Struktur. Bogor: IPB Press.

[JSA] Japanese Standard Association. 2003. Japanesse Industrial Standard Particle Board JIS A 5908. Tokyo: Japanese Standard Association.

Kawai S, Sasaki H, Nakaji M, Makiyama S, Morita S. 1986. Physical properties of low-density particleboard. Wood Research. 72: 27-36.

Maloney TM. 1993. Modern Particleboard and Dry-Process Fibreboard Manufacturing. Madison: Forest Products Society.

Maulana MI, Nawawi DS, Wistara NJ, Sari RK, Nikmatin S, Maulana S, Park SH, Febrianto F. 2018. Perubahan kadar komponen kimia bambu andong akibat perlakuan steam. JITKT. 16(1):83-92.

Maulana MI. 2019b. Sifat dasar tujuh jenis bambu untuk pembuatan nanoselulosa [Tesis]. Bogor: Institut Pertanian Bogor.

Maulana S, Purusatama BD, Wistara NJ, Sumardi I, Febrianto F. 2016. Pengaruh perlakuan steam pada strand dan shelling ratio terhadap sifat fisis dan mekanis oriented strand board bambu. JITKT. 14(2):136-143.

Maulana S, Busyra I, Fatrawana A, Hidayat W, Sari RK, Sumardi I, INJ, Lee SH, Kim NH, Febriato F. 2017 
Improvement the properties of oriented bamboo strand board by heat treatment of bambu strands. J Korean Wood Sci and Tech. 45(6):872-882.

Maulana S. 2018. Sifat fisis, mekanis, dan keawetan oriented strand board bambu andong dan betung dengan perlakuan steam pada strand [Tesis]. Bogor: Institut Pertanian Bogor.

Maulana S. 2019a. Peningkatan kualitas papan untai bambu berarah melalui modifikasi kimia dan fisik [Disertasi]. Bogor: Institut Pertanian Bogor.

Maulana S, Gumelar Y, Fatrawana A, Maulana MI, Hidayat W, Sumardi I, Wistara NJ, Lee SH, Kim NH, Febrianto F. 2019. Destructive and non-destructive tests of bamboo oriented strand board under various shelling ratios and resin contents. $J$. Korean Wood Sci. Technol. 47(4):519-532.

Nuryatin N. 2012. Vascular bundle pattern as predictor of bamboo utilization. [Desertasi]. Bogor: Institut Pertanian Bogor.

Nuryawan A, Massijaya MY, Hadi YS. 2008. Sifat fisis dan mekanis oriented strands board (OSB) dari akasia, ekaliptus, dan gmelina berdiameter kecil: pengaruh jenis kayu dan macam aplikasi perekat. JITKT. 1(2):60-66.

Saad S, Hilal. 2012. Pengaruh komposisi face-core terhadap sifat fisik dan mekanis oriented strand board dari bambu dan eceng gondok. $J$ Perennial. 8(2):75-79.

Sumardi I, Ono K, Suzuki S. 2007. Effect of board density and layer structure on the mechanical properties of bamboo oriented strandboard. $J$ wood Sci. 53:510-515.

[SBA] Structural Board Assoaciation. 2005. Oriented Strand Board in Wood Frame Construction. USA: Structural Board Association.

Tsoumis G. 1991. Science and Technology of Wood: Structure, Properties, Utilization. New York: Van Nostrand Reinhold.

Widjaja EA, Rahayuningsih Y, Setijo J, Rahajoe, Ubaidillah R, Maryanto I, Walujo EB, Semiadi G. 2014. Kekinian Keragaman Hayati Indonesia. Jakarta: LIPI Press.

Zhang M, Wong ED, Kawai S, Kwon JH. 1998. Manufacture and properties of high-performance oriented strand board composite using thin strands. $J$ wood sci. 44(3):191-197. 